\title{
EXTENSÃO UNIVERSITÁRIA, EDUCAÇÃO FÍSICA E PRODUÇÃO DOCENTE:
}

\section{a experiência com fotos comentadas}

\section{Renato Sarti ${ }^{1}$ \\ Mariana Gatto Lemos de Souza dos Santos ${ }^{2}$}

\section{RESUMO}

$\mathrm{O}$ presente relato de experiência tem o objetivo de socializar uma ação de extensão desenvolvida no contexto do projeto "Kitangu: Educação Física na Educação Infantil”. Dentro da página virtual do referido projeto, tem sido organizada uma seção chamada "Foto Comentada", que consiste em um espaço de publicação de fotos e textos reflexivos de profissionais da educação (licenciandos, professores e educadores) sobre suas experiências com a Educação Infantil. Para dialogar com a proposta em tela, foram mobilizados alguns referenciais da Extensão Universitária na perspectiva popular e da formação de professores. No exercício reflexivo, foi possível tecer dois apontamentos relacionados à potencialidade dialógica do espaço e as pistas de materialização do cruzamento da fronteira Universidade/Escola.

Palavras-chave: rede social; saberes docentes; educadores.

\section{EXTENSIÓN UNIVERSITARIA, EDUCACIÓN FÍSICA Y PRODUCCIÓN DOCENTE: la experiencia con fotos comentadas}

\section{RESUMEN}

Zl presente relato de experiencia tiene como objetivo socializar una acción de

Eextensión desarrollada en el contexto del proyecto "Kitangu: Educación Física en Educación Infantil”. Dentro de la página virtual del referido proyecto se ha organizado una sección denominada "Foto comentada", que consiste en un espacio para la publicación de fotografías y textos reflexivos por parte de profesionales de la educación (egresados, docentes y educadores) sobre sus experiencias con la Educación Infantil. Para dialogar con la propuesta, se movilizaron algunos referentes de Extensión Universitaria en la perspectiva popular y en la formación de docentes. En el ejercicio reflexivo se pudieron realizar dos apuntes relacionados con el potencial dialógico del espacio y las pistas de materialización del cruce de la frontera Universidad / Escuela.

Palabras clave: red social; conocimiento de los profesores; educadores.
Doutorando em Educação em Ciências e Saúde pela Universidade Federal do Rio de Janeiro

2 Licencianda em Educação Física pela Universidade Federal do Rio de Janeiro. 


\title{
UNIVERSITY EXTENSION, PHYSICAL EDUCATIONANDTEACHINGPRODUCTION: the experience with commented photos
}

\begin{abstract}
The present experience report aims to socialize an extension action developed 1 in the context of the project "Kitangu: Educação Física na Educação Infantil". Within the virtual page of the aforementioned project, a section called "Commented Photo" has been organized, which consists on a space for publishing photos and reflective texts by education professionals (undergraduates, teachers and educators) about their experiences with Early Childhood Education. In order to dialogue with this proposal, some references of University Extension were mobilized in the popular perspective and in the formation of teachers. In the reflective exercise, it was possible to make two notes related to the dialogic potential of that space and the clues about the materialization of the crossing of the University/School border.
\end{abstract}

Keywords: social network; teaching knowledge; educators.

\section{INTRODUÇÃO}

Como estruturas constituintes do contexto do ensino superior brasileiro, a ExAtensão Universitária e a formação de professores são espaços que vêm apresentando recorrente interlocução. Alguns trabalhos vêm trazendo as mais diversas formas de diálogo entre essas duas funções da Universidade: a Extensão como cenário, Extensão na aproximação com a prática profissional e a Extensão em um projeto amplo de formação. Como primeira possibilidade, muitas pesquisas têm lançado mão dos projetos de extensão enquanto cenário para a construção e coleta de dados, colocando-a como estrutura contextual (LAMBACH; MARQUES, 2OI4; LOPES; FEITOSA, 2OII; AIRES; LAMBACH, 2OII).

A articulação entre formação de professores e Extensão tem revelado também a construção de espaços de aproximação entre Universidade/Escola, sobretudo, possibilitando o acesso do licenciando à realidade social/profissional (SILVA; PENHA; GONÇALVES, 20I7; ALVES, 2OI5). E, em participação em longo prazo, a relação Extensão/formação vem desenhando uma maturidade pedagógica dos licenciandos envolvidos (HIRAMA; MATOS; JOAQUIM; MONTAGNER, 2OI6). Neste mesmo sentido, além da inserção do professor em formação na escola, Tonin e Scheid (2OI2) levantam outras duas contribuições fundamentais desta aproximação: a viabilidade da formação continuada e a possibilidade de melhoria do ensino da unidade escolar.

No entanto, problematizando a avaliação deste impacto da Extensão na formação profissional, Santos (2OIO, p.I5), com sua lente voltada para o princípio indissociável das ações da Universidade, sinaliza para o fortalecimento de um entendimento ampliado de formação do graduando. Assim, o autor advoga para um "horizonte mais amplo de estudo e produção e socialização de conhecimentos, e isso somente será possível com a indissociabilidade entre os eixos que sustentam o conceito e as ações da Universidade no terceiro milênio: o ensino, a pesquisa e a extensão".

Assim, conectado com este debate acerca da relação Extensão Universitária/ Formação de Professores, o referido trabalho busca socializar os resultados de uma ação de extensão desenvolvida no contexto do projeto "Kitangu: Educação Física na Educação Infantil”, protagonizada por professores da Educação Básica, licenciandos e outros profissionais de ensino. Dentro da página virtual do referido projeto, tem 
sido organizada uma seção chamada "Foto Comentada", que consiste em um espaço de publicação de fotos e textos reflexivos sobre produções pedagógicas no contexto da Educação Infantil.

\section{EXTENSÃO UNIVERSITÁRIA, FORMAÇÃO E PRODU- ÇÃO DOCENTE}

Extensão Universitária e a formação de professores no Brasil vem experimenAtando transformações diversas e estão inseridas dentro de um campo de disputa de concepções e sentidos. A Extensão vem sendo atravessada por uma conjuntura de crescimento dentro das políticas públicas e instituições de ensino superior. No entanto, as compreensões sobre Extensão têm encaminhado movimentos entre os desenhos assistencialistas e não assistencialistas. No campo da formação de professores, o modelo de formação aplicacionista ou modelo $3^{+}$I vem sendo problematizado nos últimos anos com a ascensão de novas concepções sobre a formação de professores. Em suma, a referida seção tem por objetivo situar teoricamente o presente trabalho, delineando os entendimentos que vêm sustentando as ações formativas do projeto de extensão "Kitangu: Educação Física na Educação Infantil”.

Na travessia do século XX, a Extensão brasileira parte de uma presença pontual na primeira década, passa pelas regulamentações iniciais em I93I, ganha mobilização popular dentro da Reforma Universitária nos anos de 1960 e alcança sua constitucionalidade em I988, com forte atuação do recém-criado Fórum de Pró-reitores da Extensão das Universidades Públicas Brasileiras (FORPROEX), que foi primordial na conformação das políticas atuais (PAULA, 2OI3).

Este trajeto foi atravessado sobremaneira pela atuação de Paulo Freire, com forte impacto na compreensão sobre a relação entre a Universidade e os demais segmentos da sociedade. Diante de uma Extensão balizada pela prestação de serviços e pela lógica assistencialista, Freire (2OI3) questiona o termo "extensão", desenvolve a ideia de comunicação universitária e apresenta desafios fundamentais de superação de uma "Educação Bancária" e "mecanicista". Deste modo, o autor denunciou que o termo "extensão" carregava em seu sentido "a ação de levar, de transferir, de entregar, de depositar algo em alguém" (FREIRE, 2OI3, p.I7). A ideia de comunicação vem articulada com o conceito de dialogicidade como essência da educação como prática de liberdade, assinalando a emergência do comunicar-se sobre o comunicado, ou seja, estabelecer uma relação de troca entre educador e educando (FREIRE, I987).

Fundada nos conceitos freirianos, a Extensão Popular defende uma nova forma de interlocução entre a Universidade com os demais espaços sociais e, sobremaneira, busca situar-se no seio de uma pedagogia libertadora e dialógica (CRUZ, 20I8). Para o autor, as práticas empreendidas na esteira da Extensão Popular têm buscado ancoragem em dois principais objetivos epistemológicos: responder aos desafios comunitários por meio da mobilização dos trabalhos, lutas e do pensamento crítico; e fortalecer a construção de uma ação universitária emancipadora e combativa frente à desigualdade e exclusão social. Deste modo, nos últimos anos, é possível destacar o surgimento da Articulação Nacional de Extensão Popular (Anepop) como um movimento amplo de organização dos atores sociais que vêm construindo e provocando as estruturas universitárias e as suas interlocuções com os segmentos sociais (CRUZ, 2OI3). Em suma, esta concepção traz a centralidade do diálogo com as classes populares, seus interesses e seus saberes, reivindicando transformações profundas no agir universitário (BENINCÁ; CAMPOS, 2OI7).

Desafiada pelo imperativo de aproximação entre Universidade/Escola, a formação de professores tem buscado a superação de condições impostas historicamente pelo predomínio do modelo de formação $3^{+}$I, ou seja, a organização formativa composta por três anos de bacharelado na área específica e um ano de complementa- 
ção pedagógica (SAVIANI, 2009). Assim, novos apontamentos têm buscado colocar a Escola e os conhecimentos pedagógicos com maior destaque e, nesta seção, será sublinhada a proposição do "terceiro espaço" e do "cruzamento de fronteiras" de Zeichner (2OIO) como um novo paradigma para a epistemologia dos espaços de formação de professores.

A criação destes espaços híbridos ganha sustentação na perspectiva de superar a exacerbada hierarquia dos conhecimentos acadêmicos em relação aos conhecimentos comunitários e profissionais. Diante disso, Zeichner (2OIO) elenca alguns tipos de "cruzamento de fronteiras" entre Universidade/Escola: contratação de professores da Educação Básica para as Universidades, disciplinas e as experiências de campo, professores híbridos (atuantes Universidade/Escola), valorização dos conhecimentos comunitários e a produção dos docentes da Educação Básica dentro do currículo de formação. Para diálogo direto com o referido relato de experiência, destaca-se este último cruzamento de fronteira proposto e sua potencialidade de valorização dos saberes e conhecimentos construídos no contexto da prática profissional e seus possíveis impactos na formação inicial dos professores. Desse modo, esse cruzamento pode possibilitar uma interlocução rica entre os conhecimentos acadêmicos, historicamente presentes nos componentes curriculares dos cursos, e os conhecimentos profissionais, marginalizados e de menos prestígio.

Em suma, frente a um projeto situado no ponto de encontro entre a Extensão Universitária e a formação de professores, o presente relato de experiência busca conversar com estes espaços a partir de uma compreensão popular, dialógica e comunitária, atentando para os saberes e interesses circulantes entre a Universidade e a Escola.

\section{FRONTEIRAS METODOLÓGICAS}

$\mathrm{O}$ contexto metodológico do referido trabalho é delimitado por algumas fronteiras: o contexto de produção da ação de extensão, o levantamento das publicações produzidas, a identificação de enredos, atrizes/atores e autoras/autores, os olhares para o alcance das produções e a criação da Nuvem de Palavras do conteúdo das publicações. Desse modo, o presente relato de experiência conta com a apresentação e a reflexão sobre a ação de extensão "Foto Comentada", que tem seu contexto de produção no projeto "Kitangu: Educação Física na Educação Infantil” da Universidade Federal do Rio de Janeiro. As fotos foram enviadas pelos autores/autoras por meio de convite e demanda espontânea. Devidamente contextualizado, o trabalho levanta as onze publicações realizadas na página virtual do projeto, identificando a autoria dos textos, assinalando as pessoas em protagonismo nas fotos e estabelecendo um olhar analítico em relação ao alcance das produções postadas.

Em suma, o relato de experiência conta com quatro atos principais: descrever as atrizes e os atores das fotos, identificar as autoras e os autores, analisar os enredos das produções e levantar o alcance das publicações. Para a compreensão da presença das atrizes e atores foram mobilizados alguns aspectos da Análise Semiótica Social (MAVERS; KRESS, 2OI5), compreendendo-a como teoria geral da produção de significados dentro de uma perspectiva multimodal (música, imagem, trilha sonora, etc). Para o levantamento das autoras e autores das fotos comentadas, foi desenvolvido um olhar descritivo dos lugares ocupados por esses produtores de material para a página. Sobre o alcance das publicações, foram utilizadas as ferramentas da rede social que reúnem dados sobre as interações, curtidas e engajamento. Para o entendimento dos enredos desenvolvidos, foram mobilizados os referenciais da Análise de Conteúdo (BARDIN, 2OI6) e, como ferramenta complementar, a Nuvem de Palavras. Em um último momento, na tentativa de enriquecer a reflexão sobre a ação, revelar as temáticas mais sensíveis no material e, principalmente, deixar novas questões para reflexões futuras, foi construída uma Nuvem de Palavras (NPs) a partir dos textos das fotos comentadas. Criada pelo software Wordle@, a NPs consiste em 
representações gráficas das palavras utilizadas em um texto, no qual a incidência de cada termo aparece traduzido por seu tamanho na imagem (VILELA; RIBEIRO; BATISTA, 202O).

\section{O PROJETO KITANGU, SUAS AÇÕES E O TRANSPAS- SAR DE FRONTEIRAS}

S debates sobre a inserção da Educação Física no segmento da Educação Infantil têm se intensificado, sobretudo, após a promulgação da Lei de Diretrizes e Bases da Educação Nacional (LDB 9394/I996), quando a Educação Infantil passa a ser considerada uma das etapas da Educação Básica e a Educação Física torna-se um componente curricular obrigatório de todas as etapas de ensino. Assim sendo, diante do entendimento deste segmento escolar enquanto um espaço de diálogo e atuação da Educação Física, surge o projeto de extensão "Kitangu: Educação Física na Educação Infantil”. Construído no seio da Escola de Educação Física e Desportos da Universidade Federal do Rio de Janeiro (EEFD/UFRJ), o projeto objetiva a construção de possibilidades para "cruzar as fronteiras" entre Escola/Universidade, a partir de espaços dialógicos para as reflexões sobre os desafios e avanços da disciplina nessa etapa de ensino.

Na intenção de oferecer subsídios para o cumprimento de seu objetivo principal, o projeto tem desenvolvido suas ações em três cenários, a saber: ensino, produções pedagógicas e formação. Como enfoque principal do relato em tela, o cenário de formação foi construído com o propósito de fomentar as trocas de saberes com os diferentes sujeitos envolvidos no campo educacional. Nesse sentido, para além da ideia de público-alvo, fazem parte do público-participante desse cenário professores(as) da Educação Básica, professores(as) em formação (licenciandos e licenciandas), professores(as) universitários(as) e os(as) demais profissionais da educação.

A atuação do referido cenário está centrada na elaboração de seis ações de extensão (quadro I): Kitangou: reflexões sobre o brincar, Kitangu no Cast, Educação Física na Educação Infantil em I minuto, Encontro de Educação Física na Educação Infantil, Kitangu na roda: Extensão Universitária, Educação Física e Educação Infantil em debate e Fotos comentadas.

Quadro I: Ações do cenário de formação do projeto.

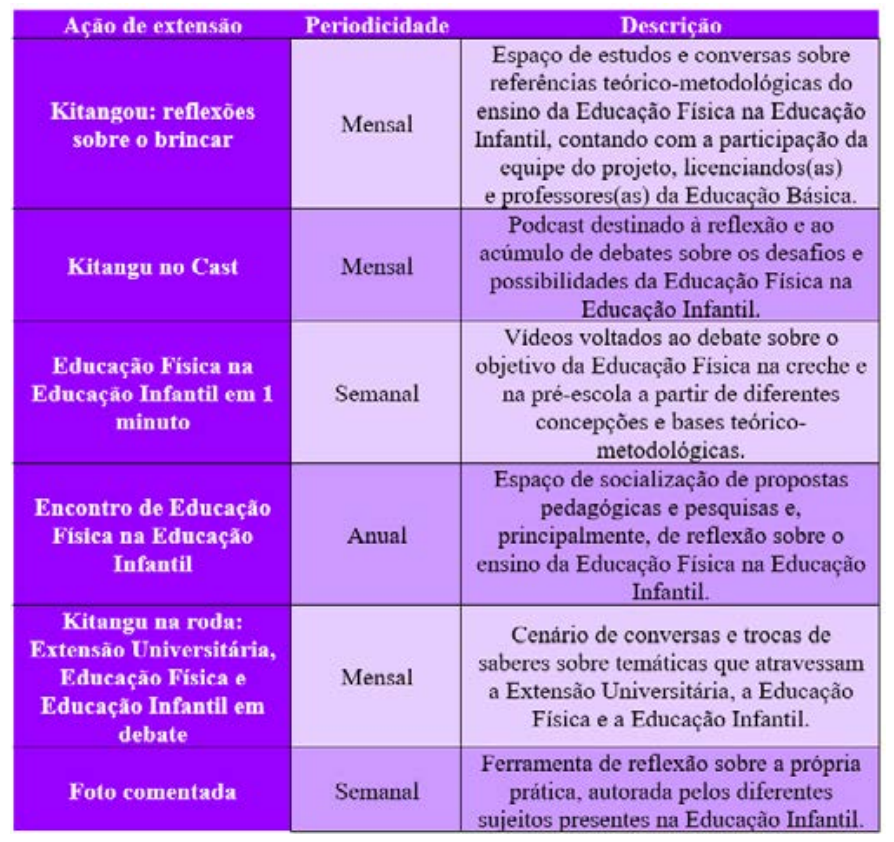

Fonte: Os autores, 2020 . 
Diante das ações citadas anteriormente, o presente relato tem como recorte a reflexão sobre a experiência com as fotos comentadas que têm sido ancoradas na página virtual do Instagram do projeto (@kitangu.eefd). A referida ação busca posicionar-se enquanto uma ferramenta rica para a reflexão sobre a prática profissional, além de proporcionar a interlocução entre Universidade/Escola e, sobretudo, a inserção da produção docente da Educação Básica dentro do currículo de formação universitária.

\section{FOTOS COMENTADAS, ENREDOS, ATRIZES E AUTO- RAS}

entro do contexto do projeto "Kitangu: Educação Física na Educação Infantil”, a ação de extensão "Foto Comentada" é o cenário principal para as reflexões desenvolvidas nessa seção. O palco é composto por atrizes/atores, autoras/ autores, enredos e espectadoras/espectadores do espetáculo. As onze fotos comentadas, já publicadas anteriormente na página virtual do projeto, são as produções que recebem a lente de análise e apresentam diferentes características de autoria, protagonismo, histórias e interações. A autoria do material contou com a participação de professores(as) da Educação Básica, professores(as) em formação (licenciandos e licenciandas), professores(as) universitários(as) e os(as) demais profissionais da educação. Além da pluralidade de autoras/autores, o espaço tem contado também com a diversidade de atrizes/atores em protagonismo nas fotos e com a variedade de temáticas em meio aos comentários, os enredos (quadro 2).

Quadro 2: Levantamento das características das fotos comentadas.

\begin{tabular}{|c|c|c|c|}
\hline $\begin{array}{l}\text { Autoras e } \\
\text { Autores }\end{array}$ & $\begin{array}{l}\text { Atrizes e } \\
\text { Atores }\end{array}$ & Enredo & $\begin{array}{l}\text { Alcance e } \\
\text { interações }\end{array}$ \\
\hline \multirow{7}{*}{$\begin{array}{l}\text { Professores(as) } \\
\text { da Educação } \\
\text { Básica }\end{array}$} & $\begin{array}{l}\text { Professora } \\
\text { e crianças }\end{array}$ & $\begin{array}{l}\text { Reflexão sobre infâncias, } \\
\text { contcúdos c docência }\end{array}$ & 263 \\
\hline & Crianças & $\begin{array}{l}\text { Reflexão sobre a própria } \\
\text { prática e sobre o objetivo da } \\
\text { Hducação Hisica na } \\
\text { Educacão Infantil }\end{array}$ & 264 \\
\hline & $\begin{array}{l}\text { Professora } \\
\text { e crianças }\end{array}$ & $\begin{array}{c}\text { Reflexão sobre a própria } \\
\text { prática e sobre o objetivo da } \\
\text { Educação Física na } \\
\text { Educação Infantil }\end{array}$ & 244 \\
\hline & Crianças & $\begin{array}{c}\text { Reflexão sobre as infâncias e } \\
\text { a própria prática }\end{array}$ & 212 \\
\hline & $\begin{array}{l}\text { Professora } \\
\text {, professor } \\
\text { e crianças }\end{array}$ & $\begin{array}{c}\text { Reflexão sobre a própria } \\
\text { prática e sobre o objetivo da } \\
\text { Educação Física na } \\
\text { Educação Infantil }\end{array}$ & 208 \\
\hline & Criança & $\begin{array}{l}\text { Reflexão subre a própria } \\
\text { prática }\end{array}$ & 216 \\
\hline & $\begin{array}{l}\text { Professor } \\
\text { e crianças }\end{array}$ & $\begin{array}{l}\text { Reflexão sobre a própria } \\
\text { prática }\end{array}$ & 256 \\
\hline \multirow{3}{*}{$\begin{array}{l}\text { Professores(as) } \\
\text { em formação }\end{array}$} & $\begin{array}{l}\text { Professora } \\
\text {, professor } \\
\text { e crianças } \\
\end{array}$ & $\begin{array}{c}\text { Reflexão sobre a própria } \\
\text { prática }\end{array}$ & 424 \\
\hline & Crianças & $\begin{array}{l}\text { Reflexão sobre a própria } \\
\text { prática }\end{array}$ & 170 \\
\hline & $\begin{array}{l}\text { Professor } \\
\text { e crianças }\end{array}$ & $\begin{array}{c}\text { Reflexão sobre a própria } \\
\text { prática }\end{array}$ & 342 \\
\hline $\begin{array}{l}\text { Demais } \\
\text { profissionais da } \\
\text { educação }\end{array}$ & Criança & $\begin{array}{l}\text { Reflexão sobre a própria } \\
\text { prática c sobrc os objetivos } \\
\text { da Educação Infantil }\end{array}$ & 215 \\
\hline
\end{tabular}

Fonte: Os autores, 2020 . 
Mesmo não sendo objetivo central do referido relato, o número das interações e dos alcances virtuais do conjunto de fotos pode oferecer contornos para a constituição de um espaço de circulação e troca de saberes. Nesta perspectiva, com a média aproximada de 256 interações por foto, a ação em tela demonstra sua aderência a um entendimento dialógico e popular de Extensão. Entretanto, as interlocuções virtuais não são os únicos indicadores que delineiam essa compreensão de Extensão. As pistas também estão no protagonismo das(os) professoras(es) e demais profissionais da Educação Básica na autoria das produções publicadas.

No que se refere à autoria das fotos comentadas, a ação em questão garantiu a participação de diferentes profissionais em diálogo com a Educação Infantil, destacando-se a presença de professores(as) da Educação Básica. Deste modo, a diversidade de autoras/autores tem oferecido pistas para enxergar nas fotos comentadas o conceito de "terceiro espaço" empreendido por Zeichner (2OIO), representando o "cruzamento de fronteiras" entre a Universidade e a Escola, bem como sua potencialidade para a inserção dos conhecimentos construídos no âmbito da Educação Básica na formação inicial de professores. Na foto comentada "No meio do caminho tinha uma creche" (Figura I), fica latente o espaço da produção poética da professora autora e a potência de interlocução com os professores em formação (licenciandos).

Figura I: Foto comentada de autoria de uma professora da Educação Básica.
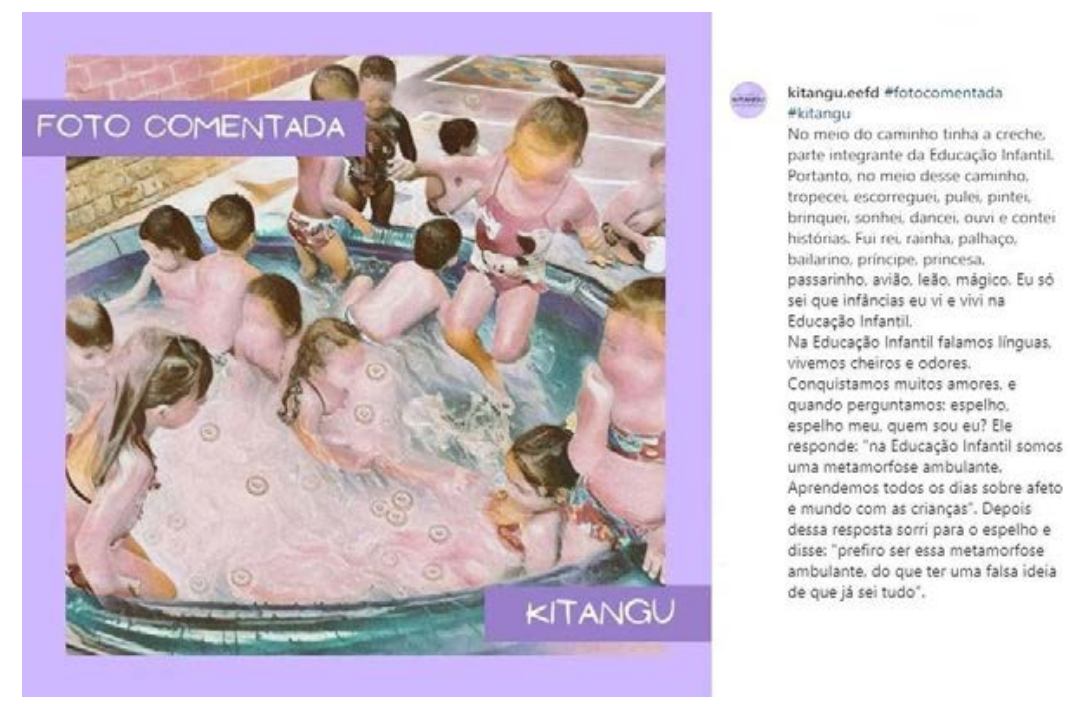

Fonte: Página do Instagram do projeto, 2020.

Destaca-se o fato de o conjunto de fotos comentadas congregar, no mesmo espaço, enquanto produtores de reflexão e conhecimento, professores da Educação Básica e professores em formação, revelando um movimento propositivo de cruzar fronteiras e possibilitar diálogos e, sobretudo, valorização dos saberes circulantes. Em se tratando dos modos não-verbais de comunicação, a foto comentada retratada pela figura s emoldura as crianças em ação em primeiro plano. A ausência de adultos no registro, em consonância com a presença de I 4 crianças da primeira etapa da Educação Básica, parece apontar para uma preocupação com o protagonismo infantil no contexto escolar. Por outro lado, em se tratando da modalidade verbal, o comentário tecido pela professora autora coloca em cena o enredo reflexivo e alguns dos detalhes que atravessam e dão textura ao seu cotidiano na Educação Infantil.

No mesmo sentido, a figura 2 traz em caráter verbal o enredo de um professor em formação e seus primeiros exercícios reflexivos. De forma não verbal, a foto comentada em questão apresenta como atores o licenciando e as crianças da Educação Infantil. Dividindo o protagonismo da cena, professor e estudantes sentados ao chão lado a lado parecem apontar não para uma hierarquia, mas para uma situação de valorização de saberes. 
Figura 2: Foto comentada de autoria de um professor em formação.
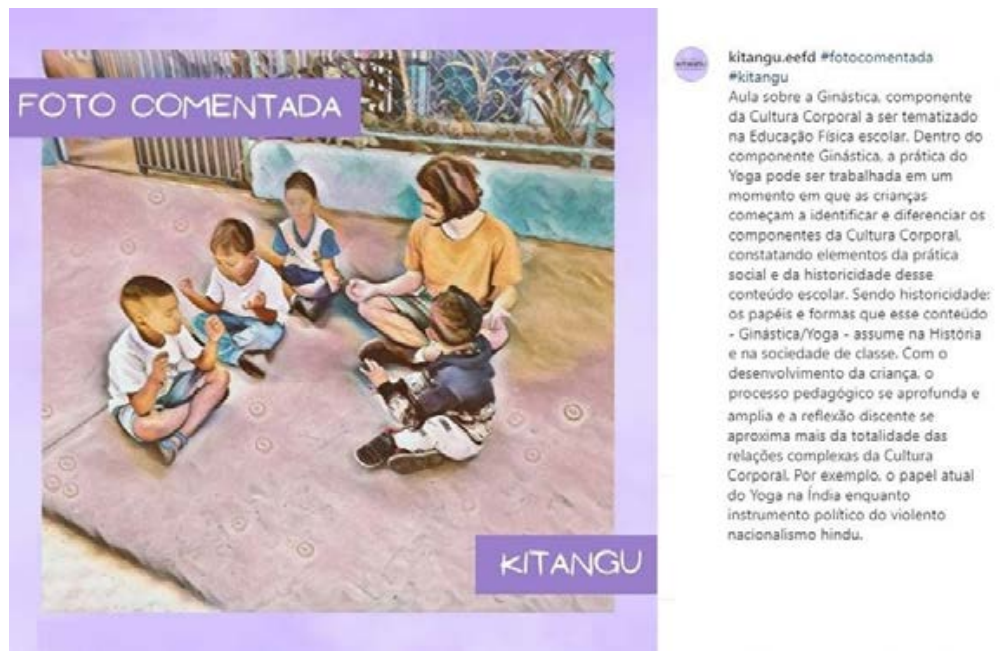

Fonte: Página do Instagram do projeto, 2020.

Os enredos das fotos comentadas passearam pelas: reflexões sobre infâncias, conteúdos e docência, objetivos da Educação Infantil, objetivos da Educação Física na Educação Infantil e reflexões sobre a prática profissional. Essa última ganhou um grande destaque nos textos produzidos, oferecendo uma riqueza de apontamentos sobre os contextos pedagógicos vividos e fotografados na Educação Infantil. Em suma, estas reflexões sobre a prática podem oportunizar a socialização de novos conhecimentos profissionais construídos pelos diversos autores e autoras, colocando-os em diálogo com os conhecimentos acadêmicos.

Sobre os atores/atrizes que protagonizaram as fotos comentadas, ficou latente o espaço majoritário das crianças e sua posição central na composição das cenas produzidas. Em cinco fotos, as crianças não dividem espaço com nenhum adulto e dominam os cenários fotografados e enredos desenvolvidos. Tal protagonismo ficou ainda mais latente com o olhar sobre a Nuvem de Palavras (NPs) dos textos postados, reafirmando a centralidade da criança, oferecendo pistas preciosas sobre o enfoque dos enredos e autores (figura 3). A Nuvem revelou ainda a grande incidência dos termos "educação", "infantil" e "escola", no que se refere ao contexto de produção, e as palavras "ginástica", "corporal" e "cultura", no que tange à área específica da Educação Física. No entanto, um aspecto chamou atenção em relação à ausência das palavras como "brincadeira" e "jogo", dois componentes da cultura corporal e conteúdo da Educação Física escolar.

Figura 3: Nuvem de Palavras gerada a partir dos textos das fotos comentadas.

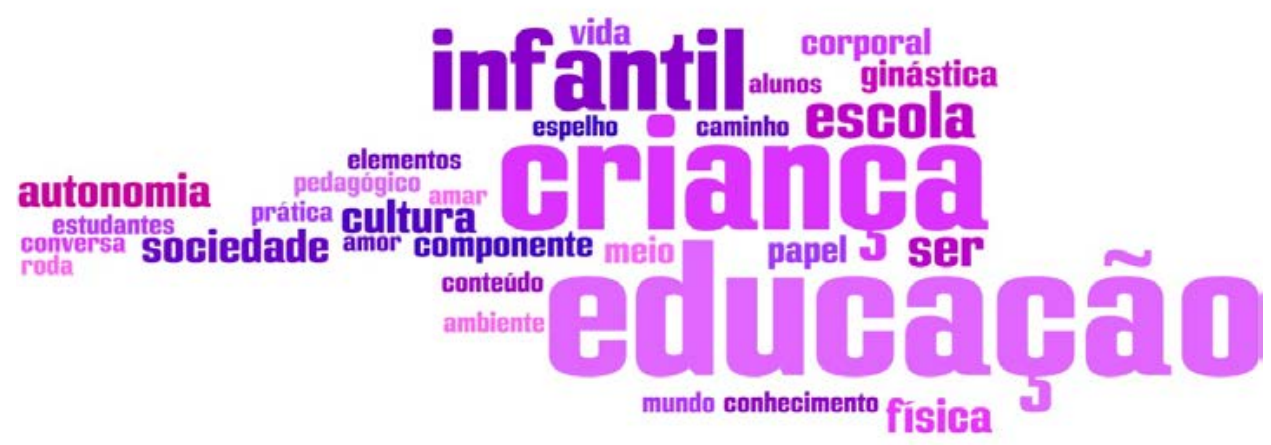

Fonte: Os autores, 2020 . 
Dessa maneira, a NPs oferece pistas instigantes sobre o protagonismo da criança no contexto da Educação Infantil, colocando nela a centralidade das ações pedagógicas. Esse espaço de destaque vem acompanhado com termos importantes para uma compreensão sobre as interlocuções desenhadas nos enredos, com destaque para "sociedade", "conhecimento", "vida", "autonomia" e "mundo". Tais incidências abrem lacunas para uma análise do conteúdo mais profunda para o entendimento das concepções atribuídas às referidas palavras.

Em suma, o olhar para o conjunto de produções das fotos comentadas, suas autorias, suas histórias e seus protagonistas traz pistas relevantes sobre a constituição de um espaço compartilhado entre os conhecimentos acadêmicos e da prática profissional, entre os(as) professores(as) da Educação Básica e os professores em formação e, sobretudo, os cruzamentos de fronteira entre Universidade/Escola.

\section{CONSIDERAÇÕES COMENTADAS}

$\mathrm{D}$ ante da socialização das ações do projeto "Kitangu; Educação Física na Educação Infantil" e da reflexão sobre a produção do quadro "Foto Comentada", foi possível tecer três apontamentos relacionados à potencialidade dialógica do espaço, as pistas de materialização do cruzamento da fronteira Universidade/Escola e as temáticas enredadas pelos autores e autoras. O primeiro comentário coloca a luz sobre as trocas de saberes entre os diferentes profissionais em diálogo com a Educação Infantil, assinalando a participação efetiva dos professores/professoras da Educação Básica como principais autores/autoras. O segundo apontamento ressalta a potência de construir pontes entre os dois principais espaços de formação docente: a Universidade e a Escola. Os textos e as fotos produzidas apresentam-se como importantes produções oriundas do contexto da prática profissional e com imenso valor na formação inicial e no diálogo com o campo acadêmico. O terceiro apontamento sublinha o espaço relevo da palavra "criança" no conteúdo das publicações, abrindo desafios futuros de aprofundamento na compreensão dos significados mobilizados pelos autores e pelas autoras, em seus respectivos enredos.

\section{REFERÊNCIAS}

AIRES, J. A.; LAMBACH, M. Contextualização do ensino de Química pela problematização e alfabetização científica e tecnológica: uma possibilidade para a formação continuada de professores. Revista Brasileira de Pesquisa em Educação em Ciências, Belo Horizonte, v. IO, n. I, I2 fev. 2OII. Disponível em: https://periodicos. ufmg.br/index.php/rbpec/article/view/3984/2548 Acesso em 29 set. 2020.

ALVES, Francivaldo Alves. A extensão universitária e formação docente em história no interior da Amazônia. Revista Conexão UEPG, Ponta Grossa, v. II, n. I, p.28-35, jan./abr. 20I5. Disponível em: https://revistas2.uepg.br/index.php/conexao/article/view/6339. Acesso em 29 set. 2020.

BARDIN, L. Análise do Conteúdo. Edição Revista e Ampliada. São Paulo: Edições Setenta, 20I6. 279p.

BENINCÁ, Dirceu; CAMPOS, Fernando Silva. S. Extensão Popular: uma proposta transformadora para a educação superior. Dialogia, São Paulo, n. 27, p. I45-I56, set./dez. 20I7. Disponível em: https://periodicos.uninove.br/index.php?journal=dialogia\&page $=$ article\&op $=$ view\&path ${ }_{5} \mathrm{~B} \%_{5} \mathrm{D}={ }_{72}{ }_{47} \&$ path ${ }_{5} \mathrm{~B} \%_{5} \mathrm{D}=36 \mathrm{r} 7$. Acesso em 27 set. 2020.

BRASIL. Lei n. 9.394, de 20 de dezembro de I996. Dispõe sobre as Diretrizes e Bases da Educação Nacional. Diário Oficial da União, Brasília, 
DF, 23 dez. 1996. Disponível em: http://www.planalto.gov.br/ccivil_o3/leis/ 19394.htm. Acesso em 27 set. 2020.

CRUZ, Pedro José Santos Carneiro. O significado deste livro e da Extensão Popular na construcão cotidiana de uma nova universidade. In.: CRUZ, Pedro José Santos Carneiro; VASCONCELOS Marcos Oliveira Dias; SARMENTO Fernanda Isabela Gondim; MARCOS Murilo Leandro; VASCONCELOS Eymard Mourão (Orgs.). Educação popular na universidade: reflexões e vivências da Articulação Nacional de Extensão Popular (Anepop). João Pessoa: Editora Universitária UFPB, 2OI3

CRUZ, Pedro José Santos Carneiro. Extensão popular: um movimento, um mosaico diverso de práticas e uma concepção para a reorientação do fazer universitário tradicional. In.: CRUZ, Pedro José Santos Carneiro; RODRIGUES, Ana Paula Maia Espíndola; PEREIRA, Eliana Alice Alves de Lima. Vivèncias de extensão em educação popular no Brasil, extensão e formação universitária: caminhos, desafios e aprendizagens / Organizadores: Pedro José Santos Carneiro Cruz, João Pessoa: Editora do CCTA, 2018.

FREIRE, Paulo. Pedagogia do Oprimido. I7. ed. Rio de Janeiro: Paz e Terra, I987.

FREIRE, Paulo. Extensão ou comunicação. I. ed. Rio de Janeiro: Paz e Terra, 2013.

HIRAMA, Leopoldo Katsuki; MATOS, José Arlen Beltrão de; JOAQUIM, Cássia dos Santos; MONTAGNER, Paulo César. Extensão universitária e formação do professor de educação física: contribuições a partir da permanência prolongada. Rev. Ciènc. Ext., São Paulo, v.I2, n.I, p.28-4O, 20I6. Disponível em: https://ojs.unesp. br/index.php/revista_proex/article/view/II25. Acesso em 27 set. $202 \mathrm{O}$.

LAMBACH, Marcelo; MARQUES, Carlos Alberto. Estilos de pensamento de professores de Química da Educação de Jovens e Adultos (EJA) do Paraná em processo de formação permanente. Revista Ensaio, Belo Horizonte, v.I6, n. oI, p. 85-IOO, jan./ abr. 20I4. Disponível em: https://www.scielo.br/pdf/epec/vi6ni/I983-2II7-epec-I6-OI-OOO85.pdf. Acesso em 27 set. 2020.

LOPES, R.; FEITOSA, E. Estágio extracurricular como um possível espaço de formação do professor para uso de tecnologias. Rev. Ciènc. Ext., São Paulo, v.7, n.2, p.I35-I47, 20II. Disponível em: https://ojs.unesp.br/index.php/revista_proex/ article/view/467. Acesso em 29 set. 2020.

MAVERS, Diane; KRESS, Gunther. Semiótica Social e textos multimodais. In.: SOMEKH, Bridget; LEWIN, Cathy. Teoria e Métodos de Pesquisa Social. Petrópolis: Vozes, 20I5.

SANTOS, Marcos Pereira dos. Contributos da extensão universitária brasileira à formação acadêmica docente e discente no século XXI: um debate necessário. Revista Conexão UEPG, Ponta Grossa, v. 6, n. I, p.IO-I5, jan./dez. 20IO. Disponível em: https://revistas2.uepg.br/index.php/conexao/article/view/373I. Acesso em 29 set. 2020 .

SAVIANI, Dermeval. Formação de professores: aspectos históricos e teóricos do problema no contexto brasileiro. Revista Brasileira de Educação [online], Rio de Janeiro, vol.I4, n.4O, p.I43-I55, jan./abr. 2009. Disponível em: http://www.scielo. $\mathrm{br} / \mathrm{pdf} / \mathrm{rbedu} / \mathrm{vi} 4 \mathrm{n} 4 \mathrm{O} / \mathrm{vI} 4 \mathrm{n} 4 \mathrm{OaI2}$.pdf. Acesso em o8 dez. 2020.

SILVA, Ana Maria Corrêa; PENHA, Natália Ribeiro da; GONÇALVES, Josiane Peres. Extensão universitária e formação docente: contribuições de um projeto de extensão para estudantes de pedagogia. Revista Formação@Docente, Belo Horizonte, v. 9, n. I, p. 74-86, jan./jun. 2OI7. Disponível em: https://www.metodista.br/ revistas/revistas-izabela/index.php/fdc/article/view/II92/842. Acesso em 29 set. 
2020.

TONIN, Luana Hilgert; SCHEID, Neusa Maria John. A interação entre acadêmicos de ciências biológicas e Professores de educação básica: contribuições para a Formação docente. Ensino de Cièncias e Tecnologia em Revista, Santo Ângelo, v. 2, n. 3 , p.38-48, jan./jun. 20I2. Disponível em: http://srvapp2s.santoangelo.uri.br/seer/ index.php/encitec/article/view/9I6. Acesso em 29 set. 2020.

PAULA, João Antônio de. Extensão universitária: história, conceito e propostas. Interfaces Revista de Extensão, Belo Horizonte, v. I, n. I, p. O5-23, jul./nov. 2013. Disponível em:http://www.dche.ufscar.br/extensao/Aextensouniversitriahistriaconceitoepropostasi.pdf. Acesso em: 27 set. 2020.

VILELA, Rosana Brandão; RIBEIRO, Adenize; BATISTA, Nildo Alves. Word cloud as a tool for content analysis an application to the challenges of the professional master's degree courses in health education. Millenium Journal, Viseu, n. II, p.2936, 2000. Disponível em: https://revistas.rcaap.pt/millenium/article/view/I7IO3. Acesso em 27 set. 2020.

ZEICHNER, Kenneth. Repensando as conexões entre a formação na universidade e as experiências de campo na formação de professores em faculdades e universidades. Revista Educação, Santa Maria, v. 35, n. 3, p. 479-504, set./dez. 2OIO. Disponível em: https://periodicos.ufsm.br/reveducacao/article/view/2357/I424. Acesso em 27 set. 2020 . 